\title{
Assessing Genetic Diversity using RAPD Molecular markers in Coffea canephora Pierre ex. Froehner (Robusta coffee): A Step towards Crop Improvement
}

\author{
Mallikarjun G. Awati ${ }^{3 *}$, B.S. Tambat ${ }^{2}$, G.F.D'souza ${ }^{1}$, \\ D. Venkataramanan ${ }^{1}$, M. Udaya Kumar ${ }^{3}$, C.G. Anand ${ }^{1}$ and Y. Raghuramulu ${ }^{1}$
}

${ }^{1}$ Division of Plant Physiology, Central Coffee Research Institute, Coffee Research Station577 117, Chikmagalur District, Karnataka, India

${ }^{2}$ Department of Crop Physiology, Agricultural College Hassan campus, ${ }^{3}$ GKVK campus, University of Agricultural Sciences, Bengaluru- 560 065, Karnataka, India

${ }^{3}$ Department of Biotechnology and Crop Improvement, College of Horticulture, Udyanagiri, UHS, Bagalkot-587104, Karnataka, India

*Corresponding author

\section{A B S T R A C T}

Keywords

Coffea canephora,

Genetic diversity,

Molecular markers,

Morpho-

physiological traits,

Cluster analysis,

Principal

component analysis

Article Info

Accepted:

12 November 2018

Available Online:

10 December 2018
The thirty one robusta accessions were analyzed for genetic diversity using RAPD molecular markers. Among the accessions, BR.11 indicated maximum dissimilarity with S.3325 (66 units) followed by S.3311 (61 units) and minimum dissimilarity was in BR.12 and $\mathrm{L}_{1}$ valley robusta (9 units). Three major clusters were observed on the dendrogram with a maximum SED of 63 units among the accessions of first cluster, 58 units in second cluster and lowest of 46 units in third cluster. The first cluster accessions showed morphophysiologically low root biomass, root to shoot ratio and moderately high total biomass. The second cluster accessions were with reasonably high root biomass and high root to shoot ratio. The third cluster accessions belong to high root and total biomass and water use efficiency types. The Principal Component Analysis (PCA) indicated genetic variation exists between the accessions. The accessions showed with over lapping and little tight clustering in three dimensional PCA revealed relatively low genetic diversity in Indian robusta gene pool. The contrast accessions i.e. S.3334 and $\mathrm{L}_{1}$ valley robusta with respect to root, WUE and associated physiological traits were placed apart in PCAs and differed by 138 SED units and these accessions could be used to raise the mapping population in breeding programme.

\section{Introduction}

Coffee is one of the most widely consumed beverages in the world. Commercial production of coffee beans of two species, Coffea arabica L. and Coffea canephora
Pierre ex Froehner, represents about 60 and $40 \%$ of the total coffee market, respectively. Brazil is the largest producer and exporter of coffee, contributing approximately $30 \%$ to the total production (ICO-International Coffee Organization, 2016). Genetic variations 
among individuals of same or different species lead to genetic diversity, which must be ensured for sustainability of breeding programs and continued availability of agronomically superior cultivars.

Robusta coffee (Coffea canephora) is an allogamous and self-incompatible species native to central Africa. It was introduced to India from Java between 1900 and 1905 AD with the aim to combat leaf rust disease (Ram et al., 1994). It manifests a high degree of rust resistance and highly productive at a relatively lower input level (Anon. 1985). In India, robusta coffee is predominantly grown in Karnataka, Kerala and Tamil Nadu states. Since, Coffea canephora has shown resistance towards stem borer, it is gradually replacing Coffea arabica in many parts. India is the third-largest producer and exporter of coffee in Asia, and the seventh-largest producer and fifth-largest exporter of coffee in the world. The coffee production in 2017-18 is estimated at 316,000 million tonnes (MT) and exports stood at 267,510 tonnes valued at US\$ 652.35 million (Anonymous, 2017). However, the growth and productivity of coffee is constrained by the non-availability of water particularly during rain free periods (November to March/April). It is estimated that up to $56.74 \%$ loss occurs mainly due to drought (Venkataramanan et al., 2004). Therefore, developing drought tolerance robust coffee has become necessity. Assessing genetic diversity and relatedness among the genotypes is a critical step in any breeding and crop improvement programme. Thus, screening robusta coffee genotypes for drought tolerant traits is vital. Although several other techniques are available to screen drought tolerant genotypes in plants (Anon. 1985; Venkataramanan, 1985; Saraswathy et al., 1992; Tounekti et al., 2017), the molecular marker techniques (like RAPD, AFLP, etc.) are preferred in coffee (Ram and Sreenath, 2000; Awati, 2004; Bhat,
2002; Prakash et al., 2005 and Silvestrini et al., 2008). The RAPD technique has been useful in studying polymorphism, identifying genes of interest and characterizing genetic resources. RAPD markers are more preferred as the technique is simple, versatile, relatively inexpensive and able to detect minute differences (Williams et al., 1990). In case of Coffea spp. RAPD technique has been used for different purposes like genetic diversity analysis of cultivated and wild accessions of Coffea arabica (Lashermes et al., 1996). Anthony et al., (2001) studied the genetic diversity among $C$. arabica accessions from spontaneous and sub spontaneous trees of Ethiopia.

The evaluation of genetic variability forms the basis for any crop improvement programme and its success depends on sufficient genetic variability among the genotypes to permit effective selection. Quantitative traits like root characteristics and physiological parameters are greatly influenced by environment, which reduces the progress and speed of selection programme. Hence, assessing the molecular diversity has greater relevance in tree crops with respect to breeding, selection and classification. Such information could be effectively used for selecting suitable parents for hybridization. Keeping this in view, the study was to look into the diverse robusta accessions using molecular markers for root traits, water use-efficiency morphophysiological traits and relatedness among the 31 accessions of $C$. canephora accessions.

\section{Materials and Methods}

Most of the Coffea canephora accessions were obtained from the gene pool of Central Coffee research Institute (CCRI) farm, India. In addition, some of elite accessions were collected from the planters' field (Table 1). The leaf samples collected from each accession was cleaned and dried at 37 to $40{ }^{\circ} \mathrm{C}$ 
for $48 \mathrm{hrs}$ and ground to fine powder using a "Remi mixer". The DNA was then extracted using powder following modified CTAB method (Bhat et al., 2002; Porebski et al., 1997). The DNA was purified following phenol: chloroform $(1: 1 \mathrm{v} / \mathrm{v})$ method and dissolved in TE ( $\mathrm{pH}$ 8.0) buffer for PCR analysis. Quantification was carried out by using "Hoefers Dynaquant" (Pharmacia Biotech, USA) and the quality was verified by electrophoresis on a $0.8 \%$ agarose gel. DNA amplification by polymerase chain reaction was carried out in a volume of $25 \mu \mathrm{l}$, which comprised of $25 \mathrm{ng}$ genomic DNA, $225 \mu \mathrm{M}$ each dNTP, $1.5 \mathrm{mM} \mathrm{MgCl}_{2}, 1 \mathrm{x}$ buffer, 5 pmoles primer and one unit of Taq DNA polymerase (Bangalore Genie). The amplification was performed in a thermal cycler (PTC 100, MJ Research Inc.,). Total reaction consisted of 40 cycles each consisting three steps, denaturation at $94^{\circ} \mathrm{C}$ for $1 \mathrm{~min}$, annealing at $36^{\circ} \mathrm{C}$ for $1 \mathrm{~min}$ and primer extension at $72^{\circ} \mathrm{C}$ for 2 minutes with an initial denaturation step of $95^{\circ} \mathrm{C}$ for $4 \mathrm{~min}$ and a final chain extension at $72^{\circ} \mathrm{C}$ for 6 minutes. Amplified fragments were separated on $1.2 \%$ agarose (Gibco BRL) gels containing ethidium bromide $(0.5 \mu \mathrm{g}$ per $\mathrm{ml}$ gel solution) at $50 \mathrm{~V}$ for 5-6 $\mathrm{h}$ in $1 \mathrm{x}$ Tris Borate EDTA buffer (TBE). The gels were stained with $0.5 \mu \mathrm{g}$ per $\mathrm{ml}$ of ethidium bromide and photographed under UV trans-illuminator and gels were documented by using Hero Lab Gel documentation system (Germany). PCR analysis was performed using 200 RAPD primers (decamer, Operon Technologies Inc. $\mathrm{K}, \mathrm{L}, \mathrm{M}, \mathrm{N}, \mathrm{O}, \mathrm{P}, \mathrm{Q}, \mathrm{R}, \mathrm{S}$ and T series). Only 30 primers were selected based on number of bands produced (> 4 bands). Finally, 18 primers which yielded intense and clearly separating bands were selected for genetic diversity analysis (Table 2). The dendrogram was constructed by Ward's method of clustering using minimum variance algorithm (Ward, 1963).

\section{Data analysis}

Binary coding method was used to score the gels. By visual observation each fragment was given score of ' 0 ' (for absence) or ' 1 ' (for presence). The size of each fragment (molecular weight in base pairs) was estimated using 100 bp ladder marker, which was run along with the amplified products. Given amplified product (band) was designated as polymorphic, if it was found only in $28(<90$ $\%$ of the total) accessions. By comparing all the possible pairs of accessions a distance matrix was developed (Sokal and Sneath, 1973). Dendrogram and principal component analysis (PCA) was performed using software STATISTICA.

\section{Results and Discussion}

The eighteen RAPD primers yielded a total of 256 bands in 31 robusta accessions. The number of bands per primer varied, primer OPN5 and OPP16 recorded maximum bands (20), whereas OPN20 yielded minimum bands (8). Overall, the average number of bands per primer was 14.2 (Table 3). Out of 256 bands, only 157 bands were found polymorphic $(61.3 \%)$. The amplification product profile produced by primer OPN5 is shown in Figure 1.

\section{Distance matrix}

The dissimilarity matrix constructed by using Squared Euclidean distance (SED) revealed that, BR.11 with S. 3325 was 66 units of dissimilar followed by dissimilar with S.3311 (61 units), C $\times$ R (60 units), S.3318 and S.3347 with 59 units. Among the BR (Balehonnur robusta) series, BR.11 distinctly dissimilarity with other accessions because of its least compatible with others as female parent than a pollinator might be responsible for genetic purity of the line (Sreenivasan and Vishveshwara, 1981). In the present study, 
BR.11 and S.3316 a descendant family of S.274 showed maximum dissimilarity with offspring's of S.270 robusta accessions. However, minimum dissimilarity was observed between BR.12 and $\mathrm{L}_{1}$ valley robusta (9 units) followed by S.3347 and Tetraploid, Village robusta and S.3334, S.3332 and C x R with 13, 14 and 15 units respectively. The minimum dissimilarity between BR.12 and $\mathrm{L}_{1}$ Valley robusta may be due to origin of both accessions from the seed progenies of S.275. Similarly, the clones or accessions i.e., S.3347, Tetraploid robusta, S.3327, S.4040, S.3318 raised from S.274 family showed a close similarity with each other in dissimilarity matrix constructed by SED using RAPD markers (Table 4).

\section{Dendrogram}

Cluster analysis revealed maximum SED of 138 units (Figure 2) on the dendrogram. Three major clusters were observed on the dendrogram. First cluster accessions were morpho-physiologically low root biomass, root to shoot ratio, instantaneous water use efficiency (WUE) i.e., $\mathrm{Pn} / \mathrm{g}_{\mathrm{s}}$ and $\mathrm{Pn} / \mathrm{E}$ types (Awati, 2004). The small group of second cluster accessions was coming under moderately high root biomass, low shoot and high root to shoot ratio and net assimilation rate types.

The third cluster included the accessions belong to the group of high root biomass and high total biomass types with moderately high root to shoot ratio and shoot to root ratio and high WUE ones compared to first and second group of accessions.

A maximum SED of 63 units was observed among the accessions of first cluster, 58 units in second cluster and the lowest of 46 units in third cluster. The genetic diversity between first to second and second to third clusters was 96 and 138 units of Squared Euclidian distance respectively (Figure 2). In the present study, the existed genetic base of the cultivated robusta accessions at CCRI farm is rather narrow mainly because of many accessions were originated by a single cross of S.274 and S.270. Initially, S.270 and S.274 robusta selections were derived by mass selection from the indigenous eight superior mother plants of CCRI gene bank. Among the progeny of S.270 and S.274, seventeen mother plants were identified to be superior to that of parents (Vishveshwara, 1975) and the clones collected from identified seventeen mother plants were named as Balehonnur robustas (BR series) (Srinivasan and Vishveshwara, 1980). Prakash et al., (2005) reported that majority of commercially cultivated forms of robusta coffee in India represent the selections from the descendants of initial introductions and revealed the higher amount of diversity present in the core samples than in Indian gene pool. Similarly in Arabica coffee, low genetic diversity was revealed by the analysis of RAPD markers (Bhat, 2002).

\section{Principal component analysis}

The PCA revealed similar clustering of 31 accessions as in the dendrogram. The three and two-dimensional PCA indicated that genetic variation exists between the accessions. Some of the accessions showed overlapping and little tight clustering of these accessions in three-dimensional PCA revealing a relatively low genetic diversity. Even though there is close clustering in the overall view, we could see some dispersion of the accessions on the two dimensional PCA indicating existence of variation. Some of the accessions like BR.11, BR.9 and S.3316 were placed distinctly in the analyzed PCA's. As a cross pollinated species, variation within the clones (BR.11 and BR.9 and S.3316), which were raised from S.274 and S.270 lines could be due to changes in genetic makeup of the accessions. However, the contrasting (S.3334 
and $\mathrm{L}_{1}$ valley robusta) parents used to raise the mapping population with respect to root and total biomass, root to shoot ratio, net assimilation rate, mean transpiration rate and instantaneous WUE were placed apart in both the PCAs (Figure 3 and 4).

Table.1 Robusta coffee (Coffea canephora) accessions used for analysis

\begin{tabular}{|c|c|c|}
\hline Sl. No.* & Accessions & Details of Parentage \\
\hline 1 & S.3317 & S.274 1/2 X S.270 $2 / 11$ \\
\hline 2 & Kagnalla robusta & Elite material from Kagnalla Estate \\
\hline 3 & S.4041 & BR.10 X BR.9 \\
\hline 4 & S.3309 & S. $2361^{12 / 2}$ \\
\hline 5 & S.4048 & BR.10 X BR.11 \\
\hline 6 & S.4046 & BR.9 X BR. 5 \\
\hline 7 & S.4045 & BR.4 X BR.9 \\
\hline 8 & BR.12 & S.275 X S. $275^{3 / 9}$ \\
\hline 9 & $\mathrm{~L}_{1}$ valley robusta & Coffea canephora (Robusta coffee) \\
\hline 10 & S.3349 & S. $270^{2 / 11}$ Self \\
\hline 11 & S.4040 & BR.9 X BR. 10 \\
\hline 12 & S.3332 & BR. $14^{13 / 15}$ X BR. $8^{11 / 7}$ \\
\hline 13 & S.3327 & BR. $1^{14 / 13}$ X S. $274^{11 / 16}$ \\
\hline 14 & S.3329 & BR. $1^{14 / 13}$ X BR.9 ${ }^{14 / 15}$ \\
\hline 15 & S.3322 & S. $270^{2 / 11}$ Bulk \\
\hline 16 & $\mathrm{C} \times \mathrm{R}$ & C.congensis $x$ C.canephora \\
\hline 17 & S.3325 & BR. $1^{14 / 13}$ X BR. $1^{10 / 15}$ \\
\hline 18 & S.3330 & BR. $1^{14 / 15}$ X S.274 ${ }^{17 / 1}$ \\
\hline 19 & S.3347 & BR. $9^{14 / 15}$ X BR. $1^{14 / 13}$ \\
\hline 20 & Tetraploid robusta & S.274 Seed treated with Colchicine \\
\hline 21 & S.3318 & S. $274^{1 / 2}$ X S. $274^{3 / 13}$ \\
\hline 22 & S.274 & Released Selection of Coffee Boar \\
\hline 23 & S.4042 & BR.9 X BR.11 \\
\hline 24 & S.3311 & S.2361 ${ }^{12 / 4}$ \\
\hline 25 & S.3339 & BR. $1^{21 / 15}$ X BR. $12^{15 / 8}$ \\
\hline 26 & Village robusta & S.275 Seed progeny \\
\hline 27 & S.3334 & BR. $8^{11 / 7}$ X BR. $11^{9 / 15}$ \\
\hline 28 & S.4044 & BR.9 X BR.4 \\
\hline 29 & S.3316 & S. $270^{2 / 11}$ X S. $274^{1 / 2}$ \\
\hline 30 & BR.9 & S.274 Clones \\
\hline 31 & BR.11 & S.274 Clones \\
\hline
\end{tabular}

*Serial numbers given in tables and gels represent respective $C$. canephora accessions throughout the study 
Table.2 List of Primers with their sequences used in genetic diversity of robusta (Coffea canephora) 31 accessions

\begin{tabular}{|c|c|c|c|c|}
\hline $\begin{array}{c}\text { S1. } \\
\text { No }\end{array}$ & Primer & $\begin{array}{c}\text { Sequence } \\
\text { 5'-3 }\end{array}$ & $\begin{array}{c}\text { Total no. } \\
\text { of bands }\end{array}$ & $\begin{array}{c}\text { No. of } \\
\text { Polymorphic } \\
\text { bands }\end{array}$ \\
\hline $\mathbf{1}$ & OPL18 & ACCACCCACC & 18 & 12 \\
\hline $\mathbf{2}$ & OPM13 & GGTGGTCAAG & 16 & 13 \\
\hline $\mathbf{3}$ & OPM16 & GTAACCAGCC & 16 & 11 \\
\hline $\mathbf{4}$ & OPN20 & GGTGCTCCGT & 8 & 4 \\
\hline $\mathbf{5}$ & OPN18 & GGTGAGGTCA & 14 & 10 \\
\hline $\mathbf{6}$ & OPN5 & ACTGAACGCC & 20 & 15 \\
\hline $\mathbf{7}$ & OPO12 & CAGTGCTGTG & 10 & 5 \\
\hline $\mathbf{8}$ & OPO7 & CAGCACTGAC & 16 & 9 \\
\hline $\mathbf{9}$ & OPP16 & CCAAGCTGCC & 20 & 9 \\
\hline $\mathbf{1 0}$ & OPP4 & GTGTCTCAGG & 11 & 5 \\
\hline $\mathbf{1 1}$ & OPP6 & GTGGGCTGAC & 12 & 7 \\
\hline $\mathbf{1 2}$ & OPQ15 & GGGTAACGTG & 16 & 11 \\
\hline $\mathbf{1 3}$ & OPQ5 & CCGCGTCTTG & 16 & 13 \\
\hline $\mathbf{1 4}$ & OPR1 & TGCGGGTCC & 16 & 11 \\
\hline $\mathbf{1 5}$ & OPR12 & ACAGGTGCGT & 10 & 6 \\
\hline $\mathbf{1 6}$ & OPR3 & ACACAGAGGG & 12 & 5 \\
\hline $\mathbf{1 7}$ & OPN16 & AAGCGACCTG & 15 & 5 \\
\hline $\mathbf{1 8}$ & OPT7 & GGCAGGCTGT & 10 & 6 \\
\hline & & TOTAL & $\mathbf{2 5 6}$ & $\mathbf{1 5 7}$ \\
\hline & & & & \\
\hline & & & \\
\hline
\end{tabular}

Table.3 Summary table of the primers used, number of bands per primer and percentage of polymorphic bands

\begin{tabular}{|l|l|}
\hline Total number of primers used & 18 \\
Average number of bands per primer & 14.2 \\
Number of polymorphic bands per primer & 8.7 \\
Percentage of polymorphic bands & 61.3 \\
\hline
\end{tabular}


Table.4 Dissimilarity matrix constructed by Squared Euclidean distance using RAPD data in robusta coffee

\begin{tabular}{|c|c|c|c|c|c|c|c|c|c|c|c|c|c|c|c|c|c|c|c|c|c|c|c|c|c|c|c|c|c|c|c|c|}
\hline $\begin{array}{l}\text { Ac } \\
\text { No. }\end{array}$ & $\begin{array}{c}\text { Robusta } \\
\text { Accessions }\end{array}$ & 1 & 2 & 3 & 4 & 5 & 6 & 7 & 8 & 9 & 10 & 11 & 12 & 13 & 14 & 15 & 16 & 17 & 18 & 19 & 20 & 21 & 22 & 23 & 24 & 25 & 26 & 27 & 28 & 29 & 30 & 31 \\
\hline 1 & S.3317 & 0 & 28 & 27 & 33 & 27 & 31 & 24 & 22 & 23 & 28 & 27 & 29 & 27 & 19 & 36 & 30 & 34 & 28 & 37 & 38 & 39 & 38 & 41 & 37 & 34 & 31 & 35 & 34 & 43 & 44 & 56 \\
\hline 2 & Kagnalla & & 0 & 31 & 23 & 25 & 25 & 22 & 30 & 33 & 38 & 33 & 37 & 37 & 39 & 40 & 44 & 44 & 36 & 51 & 54 & 47 & 36 & 33 & 43 & 40 & 47 & 45 & 38 & 53 & 42 & 48 \\
\hline 3 & S.4041 & & & 0 & 32 & 22 & 32 & 33 & 25 & 24 & 33 & 30 & 32 & 26 & 32 & 41 & 35 & 37 & 39 & 40 & 39 & 44 & 39 & 38 & 42 & 35 & 40 & 36 & 37 & 50 & 47 & 53 \\
\hline 4 & S.3309 & & & & 0 & 24 & 22 & 27 & 27 & 32 & 37 & 28 & 30 & 34 & 38 & 31 & 37 & 39 & 39 & 40 & 47 & 42 & 39 & 30 & 36 & 37 & 40 & 38 & 35 & 54 & 37 & 43 \\
\hline 5 & S.4048 & & & & & 0 & 22 & 27 & 21 & 24 & 27 & 26 & 30 & 28 & 34 & 39 & 31 & 37 & 33 & 38 & 43 & 42 & 27 & 28 & 34 & 29 & 32 & 34 & 29 & 42 & 41 & 43 \\
\hline 6 & S.4046 & & & & & & 0 & 21 & 23 & 24 & 31 & 28 & 32 & 28 & 40 & 35 & 37 & 43 & 35 & 42 & 39 & 44 & 37 & 28 & 40 & 37 & 36 & 38 & 25 & 50 & 37 & 43 \\
\hline 7 & S.4045 & & & & & & & 0 & 20 & 25 & 34 & 35 & 33 & 33 & 33 & 38 & 38 & 40 & 34 & 47 & 46 & 43 & 36 & 35 & 41 & 40 & 41 & 39 & 32 & 49 & 36 & 36 \\
\hline 8 & BR.12 & & & & & & & & 0 & 9 & 24 & 25 & 19 & 17 & 29 & 28 & 20 & 26 & 28 & 31 & 32 & 33 & 32 & 31 & 29 & 34 & 25 & 27 & 26 & 49 & 38 & 48 \\
\hline 9 & $\mathrm{~L}_{1}$ valley & & & & & & & & & 0 & 19 & 18 & 20 & 16 & 30 & 27 & 21 & 25 & 27 & 26 & 25 & 28 & 35 & 34 & 30 & 27 & 26 & 28 & 25 & 50 & 41 & 53 \\
\hline 10 & S.3349 & & & & & & & & & & 0 & 27 & 25 & 25 & 27 & 26 & 24 & 30 & 30 & 29 & 36 & 29 & 38 & 37 & 33 & 38 & 33 & 37 & 28 & 53 & 46 & 54 \\
\hline 11 & S.4040 & & & & & & & & & & & 0 & 16 & 22 & 28 & 25 & 23 & 25 & 37 & 28 & 29 & 28 & 35 & 32 & 26 & 27 & 32 & 32 & 29 & 52 & 43 & 57 \\
\hline 12 & S.3332 & & & & & & & & & & & & 0 & 20 & 26 & 21 & 15 & 23 & 35 & 26 & 27 & 24 & 35 & 34 & 24 & 29 & 24 & 26 & 31 & 52 & 43 & 55 \\
\hline 13 & S.3327 & & & & & & & & & & & & & 0 & 24 & 19 & 19 & 25 & 23 & 28 & 27 & 32 & 29 & 28 & 32 & 29 & 22 & 24 & 27 & 46 & 41 & 49 \\
\hline 14 & S.3329 & & & & & & & & & & & & & & 0 & 29 & 23 & 33 & 33 & 36 & 41 & 38 & 35 & 44 & 34 & 37 & 30 & 34 & 35 & 46 & 49 & 53 \\
\hline 15 & S.3322 & & & & & & & & & & & & & & & 0 & 18 & 20 & 32 & 27 & 28 & 23 & 40 & 35 & 25 & 30 & 27 & 31 & 38 & 57 & 42 & 56 \\
\hline 16 & CXR & & & & & & & & & & & & & & & & 0 & 18 & 32 & 17 & 22 & 19 & 32 & 35 & 19 & 24 & 21 & 21 & 32 & 49 & 46 & 60 \\
\hline 17 & S.3325 & & & & & & & & & & & & & & & & & 0 & 34 & 17 & 22 & 23 & 40 & 43 & 25 & 26 & 33 & 29 & 44 & 57 & 52 & 66 \\
\hline 18 & S.3330 & & & & & & & & & & & & & & & & & & 0 & 35 & 34 & 39 & 34 & 37 & 43 & 36 & 35 & 37 & 30 & 47 & 44 & 46 \\
\hline 19 & S.3347 & & & & & & & & & & & & & & & & & & & 0 & 13 & 16 & 33 & 38 & 24 & 23 & 24 & 20 & 31 & 48 & 45 & 59 \\
\hline 20 & Tetraploid & & & & & & & & & & & & & & & & & & & & 0 & 19 & 38 & 43 & 27 & 22 & 25 & 21 & 32 & 43 & 42 & 56 \\
\hline 21 & S.3318 & & & & & & & & & & & & & & & & & & & & & 0 & 29 & 36 & 18 & 23 & 24 & 20 & 35 & 52 & 43 & 59 \\
\hline 22 & S.274 & & & & & & & & & & & & & & & & & & & & & & 0 & 17 & 23 & 30 & 29 & 29 & 34 & 35 & 40 & 46 \\
\hline 23 & S.4042 & & & & & & & & & & & & & & & & & & & & & & & 0 & 26 & 35 & 32 & 34 & 27 & 44 & 35 & 41 \\
\hline 24 & S.3311 & & & & & & & & & & & & & & & & & & & & & & & & 0 & 23 & 28 & 24 & 39 & 46 & 45 & 61 \\
\hline 25 & S.3339 & & & & & & & & & & & & & & & & & & & & & & & & & 0 & 25 & 17 & 34 & 41 & 40 & 48 \\
\hline 26 & Village & & & & & & & & & & & & & & & & & & & & & & & & & & 0 & 14 & 23 & 40 & 35 & 51 \\
\hline 27 & S.3334 & & & & & & & & & & & & & & & & & & & & & & & & & & & 0 & 25 & 36 & 35 & 47 \\
\hline 28 & S.4044 & & & & & & & & & & & & & & & & & & & & & & & & & & & & 0 & 41 & 26 & 34 \\
\hline 29 & S.3316 & & & & & & & & & & & & & & & & & & & & & & & & & & & & & 0 & 43 & 41 \\
\hline 30 & BR.9 & & & & & & & & & & & & & & & & & & & & & & & & & & & & & & 0 & 22 \\
\hline 31 & BR.11 & & & & & & & & & & & & & & & & & & & & & & & & & & & & & & & $\mathbf{0}$ \\
\hline
\end{tabular}


Figure.1 A RAPD gel profile of 31 C. canephora accessions generated by the Primer OPN5

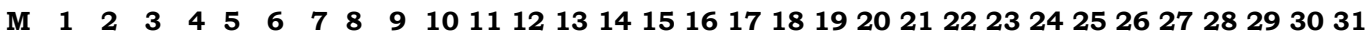

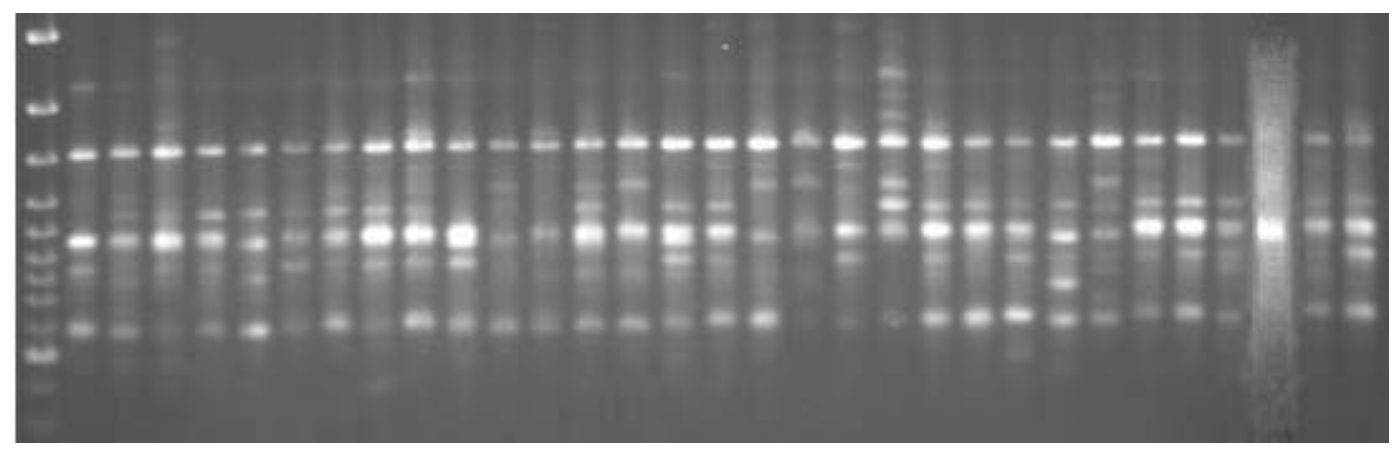

Figure.2 Dendrogram showing relationship among the 31 Coffea canephora accessions

Tree Diagram for 31 Accessions of Coffea canephora

Ward's method

Squared Euclidean distances

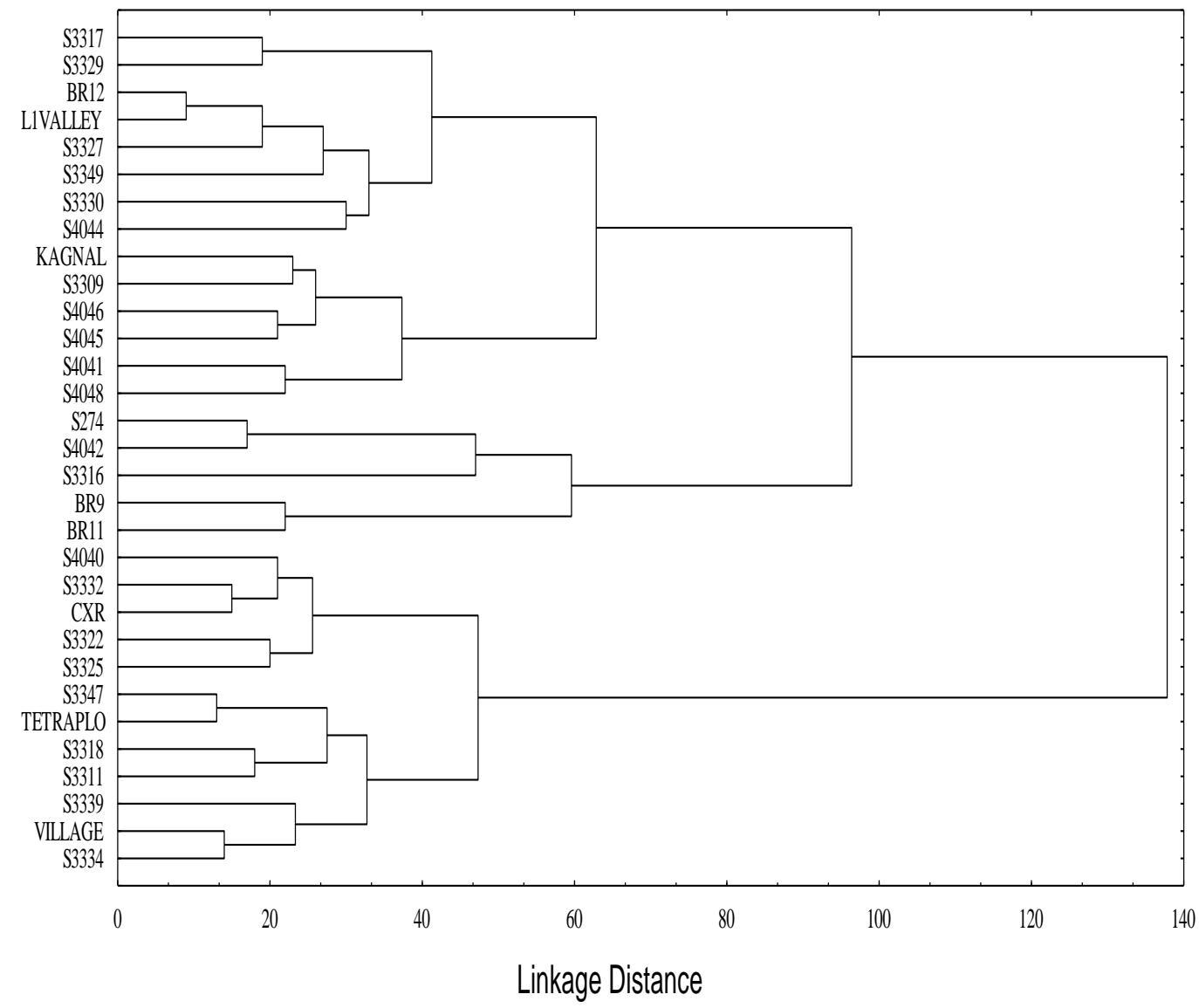


Figure.3 Three dimensional PCA showing the genetic relationship among the 31 Coffea canephora accessions

Factor Loadings, Factor 1

Rotation: Unrotated

Extraction: Principal components

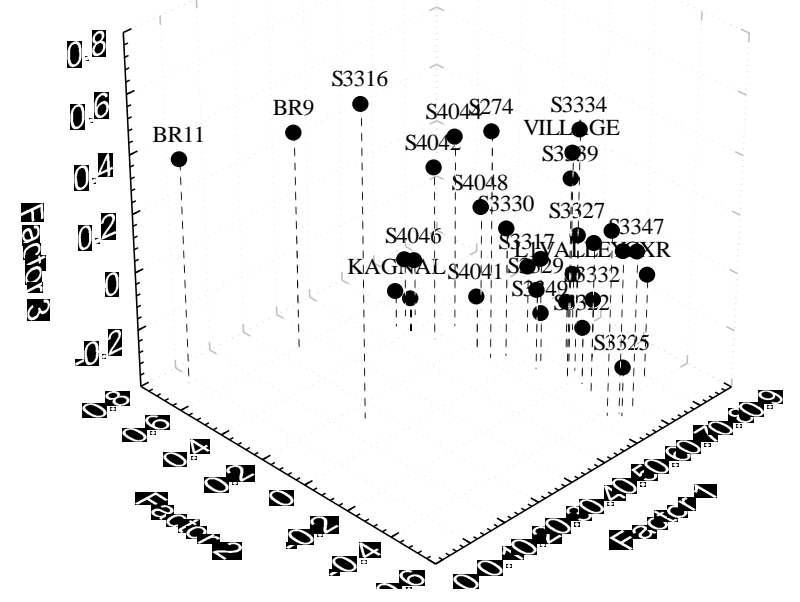

Figure.4 Two dimensional PCA showing the genetic relationship among the 31 Coffea canephora accessions

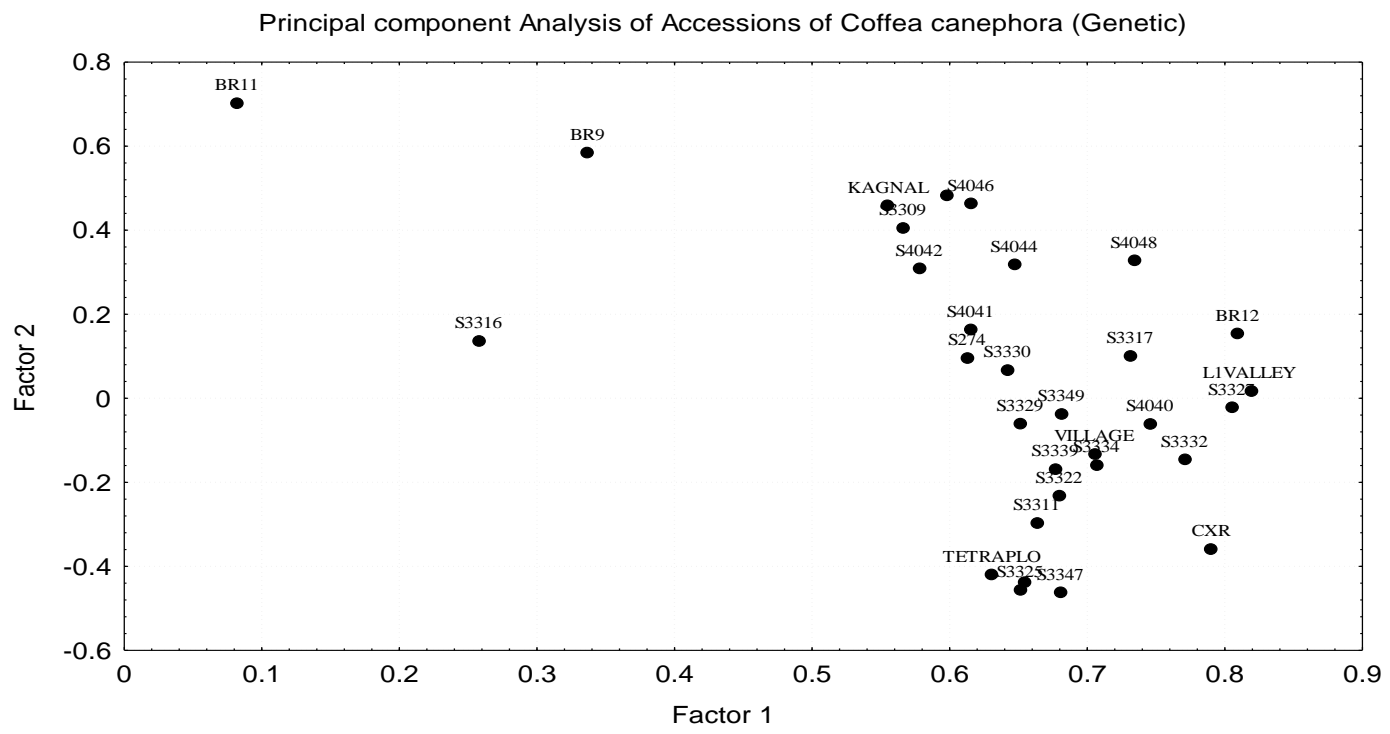

In spite of the fact that genetic diversity in $C$. canephora is low, in the present study RAPD markers could identify the differences among these accessions. For example, RAPD markers have been successfully employed to analyze the genetic diversity among the cultivated and sub-spontaneous accessions of C. arabica by Lashermes et al., (1996) and 
Anthony et al., (2001). In Coffea, RAPD markers were used to identify polymorphism in different coffee accessions (OrozcoCastillo et al., 1994; Lashermes et al., 1996) and also to analyze spontaneous and sub spontaneous $C$. arabica trees form Ethiopia (Anthony et al., 2001).

In conclusion, three and two dimensional PCA and clustering of accessions revealed that, relatively low genetic diversity in Indian robusta coffee. Among the accessions, BR.11 indicated maximum dissimilarity with S.3325 followed by a minimum dissimilarity in BR.12 and $\mathrm{L}_{1}$ valley robusta. However, S.3334 and $\mathrm{L}_{1}$ valley robusta were contrast with respect to root and total biomass, water use efficiency, root to shoot ratio, net assimilation rate, mean transpiration rate and also were placed apart in both PCAs and dendrogram and were used to raise the mapping population to study the association of markers and root traits in robusta coffee. The study confirmed the occurrence of traits diversity in robusta coffee accessions and this could be exploited in the genetic improvement of the crop through hybridization and selection. It is, however, necessary that use of more number of molecular markers with additional accessions need to be confirmed.

\section{Acknowledgements}

Authors are thankful to Department of Biotechnology, New Delhi and Coffee Board, Ministry of Commerce, Government of India for providing financial assistance and facilities to carry out the study.

\section{References}

Anonymous, 2017. Database on coffee, In: Economic and market intelligence unit, Coffee Board, Bangalore, India.

Anounymous, 1985. Coffee Guide, Research Department, Coffee Board, Bangalore,
India, Pp. 200.

Anounymous, 2004. Database on coffee, In: Economic and market intelligence unit, Coffee Board, Bangalore, India, Pp. 5.

Anthony, F., Fernandez, D., Lashermes, P. and Nicole, M. 2001. Genomics and coffee breeding for durable resistance to parasites. In: Institut recherche pour le development News Letter, Version du $14^{\text {th }}$ March.

Awati Mallikarjun, G. 2004. Molecular markers for root traits, WUE and associated physiological traits in Coffea canephora Pierre ex. Froehner. Ph.D thesis, University of Agricultural Sciences. Bangalore, India, Pp. 196.

Bhat, P.R. 2002. Phenotyping and molecular analysis of Coffea arabica L. accessions and mapping population to identify RAPD markers associated with root characteristics and associated physiological traits'. Ph.D thesis, University of Agricultural Sciences. Bangalore, India, Pp. 167.

Bhat, P.R., Sondur, S.N., Awati, M.G. and Udaya Kumar, M. 2002. An efficient method of DNA extraction from leaf samples of coffee. J. Plant. Crops, 30(3): 13-15.

ICO-International Coffee Organization 2016. Total production 2015. Available at: [http://www.ico.org/trade_statistics.asp]

Lashermes, P., Cros, J., Combes, M.C., Trouslot, P., Anthony, F., Hamon, S. and Charrier, A. 1996. Inheritance and restriction fragment length polymorphism of chloroplast DNA in the genus Coffea. Theoret. and Applied Genet., 93: 626632.

Orozco-Castillo, C., Chalmess, K.J., Waugh, R. and Powell, W. 1994. Detection of genetic diversity and selective gene introgression in coffee using RAPD markers. Theoret. and Applied Genet., 87: 934-940.

Porebski, S., Bailey, G. and Baum, B.R. 1997. Modification of a CTAB DNA extraction protocol for plants containing high polysaccharide and polyphenol 
components. Pl. Mol. Biol. Reporter, 15(1): 8-15.

Prakash, N.S., Combes, M.C., Dussert, S., Naveen, S. and Lashermes, P. 2005. Analysis of genetic diversity in Indian robusta coffee gene pool (Coffea canephora) in comparison with a representative core collection using SSRs and AFLPs. Genet. Resour. and Crop Evol., 52: 333-343.

Ram, A.S. and Sreenath, H.L. 2000. Genetic fingerprinting of coffee leaf rust differentials with RAPD markers. In: Sera T, Soccol CR, Pandey A, Roussos S (Eds.) Coffee biotechnology and quality, Proceedings of the 3rd international seminar on biotechnology in the coffee agroindustry, Londrina, Brazil. Kluwer Academic Publishers, Dordrecht, The Netherlands, Pp 197-208.

Ram, A.S., Sreenivasan, M.S. and Naidu, R. 1994. Exploitation of coffee germplasm in India. J. Coffee Res., 24(2): 107-114.

Saraswathy, V.M., Venkataramanan, D. and Ramaiah, P.K. 1992. Drought tolerance in exotic robustas. J. Plant. Crops, 20(2): 123-130.

Silvestrini, M., Maluf, M.P., Silvarolla, M.B., Guerreiro-Filho, O., Medina-Filho, H.P., Vanini, M.M.T., Oliveira, A.S., GaspariPezzopane, C.de and Fazuoli, L.C. 2008. Genetic diversity of a Coffea germplasm collection assessed by RAPD markers. Genet. Resour. and Crop Evol., 55: 901910.

Sokal, R.R. and Sneath, P.H.A. 1973. Principles of numerical taxonomy. W. H. Freeman and Co., San Francisco, USA.
Sreenivasan, C.S. and Vishveshwara, S. 1980. A study of robusta propagation: Clone vs Seedling. Indian Coffee, XLIV, Pp. 105111.

Sreenivasan, M.S. and Vishveshwara, S. 1981. Compatibility studies in Coffea canephora. In: Genetics, Plant breeding and Horticulture (PLACROSYM IV), S. Vishveshwara, (Ed.), ISPC, Kasaragod, Kerala, Pp. 278-282.

Tounekti, T., Mahdhi, M., Al-Turki, T.A. and Khemira, H. 2017. Genetic diversity analysis of Coffee (Coffea arabica L.) germplasm accessions growing in the southwestern Saudi Arabia using quantitative traits. Nat. Resour., 8: 321336.

Venkataramanan, D. 1985. Physiological studies in coffee. Ph.D. Thesis, University of Mysore, India, Pp. 157.

Venkataramanan, D., Renuka Swamy, D’Souza, G.F. and Sadananda, N. 2004. Rainfall pattern and drought situation in coffee plantations and its impact. Indian Coffee, 68(3): 10-18.

Vishveshwara, S. 1975. Some thoughts on breeding robusta coffee. In: Wynaad Coffee Growers Association Souvenier, Kerala, Pp. 11-15.

Ward, J.H. 1963. Hierarchic grouping to optimize function. J. Amer. Stat. Assoc., 58: 236-239.

Williams, J.G.K., Kubelik, A., Livak, K.J., Rafiski, J.A. and Tingey, S.V. 1990. DNA polymorphisms amplified by arbitrary primers are useful as genetic markers. Nuc. Acids Res., 18: 6351-6355.

\section{How to cite this article:}

Mallikarjun G. Awati, B.S. Tambat, G.F. D'souza, D. Venkataramanan, M. Udaya Kumar, C.G. Anand and Raghuramulu, Y. 2018. Assessing Genetic Diversity using RAPD Molecular markers in Coffea canephora Pierre ex. Froehner (Robusta coffee): A Step towards Crop Improvement. Int.J.Curr.Microbiol.App.Sci. 7(12): 1704-1714. doi: https://doi.org/10.20546/ijcmas.2018.712.198 